\title{
The genes for the inter- $\alpha$-inhibitor family share a homologous organization in human and mouse
}

\author{
Jean-Philippe Salier, ${ }^{1}$ Vera Verga, ${ }^{2}$ Janine Doly, ${ }^{3}$ Maryam Diarra-Mehrpour, ${ }^{4}$ and Robert P. Erickson ${ }^{2} *$ \\ ${ }^{1}$ Institut National de la Santé et de la Recherche Médicale, Unit-78, 76230 Boisguillaume, France; ${ }^{2}$ Department of Human Genetics, \\ University of Michigan Medical School, Ann Arbor, Michigan 48109-0618, USA; ${ }^{3}$ Institut de Recherches Scientifiques sur le Cancer, \\ CNRS UPR-37, 94800 Villejuif, France; ${ }^{4}$ Institut National de la Santé et de la Recherche Médicale, Unit-295, \\ 76800 Saint-Etienne-du-Rouvray, France
}

Received July 24, 1991; accepted September 5, 1991

\begin{abstract}
Inter- $\alpha$-inhibitor $(I \alpha I)$ and related molecules in human are comprised of three evolutionarily related, heavy $(\mathrm{H})$ chains and one light $(\mathrm{L})$ chain, also termed bikunin. The latter originates from a precursor molecule that is cleaved to yield the bikunin and another protein designated $\alpha-1$-microglobulin (A1m). The four $\mathrm{H}$ and $\mathrm{L}$ chains are encoded by four distinct genes designated $H 1, H 2, H 3$, and $L$. The $L$ and $H 2$ genes are localized onto human chromosomes (chr) 9 and 10 , respectively, whereas the $H I$ and $H 3$ genes are tandemly arranged on chr 3.

Mouse poly(A) ${ }^{+}$RNAs or endonuclease-restricted mouse DNA were analyzed by standard and pulsedfield gel electrophoresis (PFGE) techniques in agarose gels and blot-hybridized with human $\mathrm{H1}, \mathrm{H} 2, \mathrm{H} 3$ or $L$ cDNA probes. The variable sized transcripts and unique restriction fragment patterns detected with each probe indicate that four genes, including one common $L$ gene for $\mathrm{A} 1 \mathrm{~m}$ and bikunin also exist in mouse. The co-migration of $H I$ - and $H 3$-hybridizing fragments on PFGE suggests that the mouse $H I$ and $H 3$ genes are also tandemly arranged. An Msp I restriction fragment length polymorphism (RFLP) in the mouse $L$ gene (proposed symbol, Intin-4) links this gene to other genes already mapped at mouse $\mathrm{Chr} 4$ near the brown $(b)$ locus, a homologous region to the human chr $9 \mathrm{q} 32-34$ band where the human $I \alpha I L$ gene is located. Therefore, a similar number and arrangement of $I \alpha I$ genes is found in mouse and human, including the triplication of an $H$ gene ancestor. These results point to an ancient origin of this complex set of genes.
\end{abstract}

\footnotetext{
*Present address: Department of Pediatrics, University of Arizona Health Sciences Center, Tucson, Arizona 85724, USA

offprint requests to: J.-P. Salier
}

\section{Introduction}

$I \alpha I$ is a plasma glycoprotein of high $\mathrm{Mr}$ that acts as a serine protease inhibitor (reviewed in Gebhard and Hochstrasser 1986; Salier 1990). Characteristic amino acid sequences in the protease inhibitory domains of $I \alpha I$ indicate that this protein belongs to the superfamily of Kunitz-type protease inhibitors (Wachter and Hochstrasser 1979). However, the function of $I \alpha I$ in vivo still awaits complete elucidation and this function may not, or not only, be related to its protease inhibitory capacity (McKeehan et al. 1986; Salier 1990). Moreover, the recent characterization of a family of $I \alpha I$-related molecules in plasma suggests that more than one function could pertain to $I \alpha I$ family members (Salier 1990). The complex set of mRNAs and genes that encode the $I \alpha I$ family has recently been described in human (Bourguignon et al. 1985; Kaumeyer et al. 1986; Salier et al. 1987; Gebhard et al. 1988; Vetr et al. 1989; Diarra-Mehrpour et al. 1989, 1990); the information helped clarify the multipolypeptide chain structure of $I \alpha I$ and related molecules (Bourguignon et al. 1983; Jessen et al. 1988; Enghild et al. 1989). One L chain and three $\mathrm{H}$ chains are separately synthesized in the liver by four mRNAs which are designated $L, H 1$, $H 2$ and $H 3$, respectively (Salier et al. 1987; DiarraMehrpour et al. 1989; Enghild et al. 1989). The approximate sizes of the $\mathrm{L}$ or $\mathrm{H}$ chain mRNAs are 1.25 or 3.2 $\mathrm{kb}$, respectively. In human, the corresponding $L$ and $\mathrm{H} 2$ genes have been mapped by in situ hybridization to 9q32-33 and 10p14-15, respectively, whereas both $H 1$ and $H 3$ genes map to $3 \mathrm{p} 21.1-21.2$ (Diarra-Mehrpour et al. 1989). The three $H$ genes are evolutionarily related and they most likely originate from the $\mathrm{H}_{3}$ gene as an ancestor (Diarra-Mehrpour et al. 1989). Separate exons in the gene for the $\mathrm{L}$ chain precursor code for two tandem, in-frame proteins, termed $\alpha$-1-microglobulin (A1m) and bikunin that are released by posttranslational cleavage of their common $\mathrm{L}$ chain pre- 
cursor (Kaumeyer et al. 1986; Diarra-Mehrpour et al. 1990). The mature A1m molecule, another plasma glycoprotein, is neither structurally nor functionally related to the $I \alpha I$ family. In contrast, the bikunin contains two Kunitz-type protease inhibitory domains (Wachter and Hochstrasser 1979), hence its name (Gebhard et al. 1990a), and is found in all $I \alpha I$ family members studied to date (Enghild et al. 1989). $I \alpha I$ itself is made of the $H 1, H 2$ and bikunin chains, whereas other family members in plasma include: (1) pre- $\alpha$-inhibitor ( $P \alpha I)$ made of the $\mathrm{H} 3$ chain and bikunin; and (2) the so-called $I \alpha I$ derivatives which are free bikunin molecules (Enghild et al. 1989; reviewed in Salier 1990).

$I \alpha I$ and $I \alpha I$ derivatives have been found in the plasma of all mammalian species studied so far, from rodents to human (reviewed in Gebhard and Hochstrasser 1986), whereas the recently discovered $P \alpha I$ molecule has not yet been investigated in various species. However, at the present time, $I \alpha I \mathrm{cDNAs}$ and genes have been studied almost exclusively in human. Given the complexity in organization and evolution of human $I \alpha I$ genes, we were interested in studying whether or not such complexity is a recent evolutionary event. Our present results indicate that the overall organization of the four $L$ and $H$ genes existed prior to the divergent evolution of human and mouse.

\section{Materials and methods}

\section{Human cDNA probes}

The cDNA clones for $\mathrm{L}, \mathrm{H} 1, \mathrm{H} 2$ or $\mathrm{H} 3$ chains of human $I \alpha I$ were obtained from a human liver cDNA library cloned in the $\lambda$ gt11 expression vector (Salier et al. 1987). Most of these clones have been described elsewhere (Salier et al. 1987; Diarra-Mehrpour et al. 1989). Briefly, an Ava I-Ava I, 591 bp A1m-encoding cDNA and an $A v a$ I- $A v a$ I, 501 bp bikunin-encoding cDNA from clone $\lambda$ HuLITI23 (Salier et al. 1987) were used together ( $L$ probe) or separately, depending on the experiments (see Results). Together, these probes cover $87 \%$ of the full-length $\mathrm{L}$ chain cDNA. The $H I$ cDNA probe was the EcoR I-EcoR I, 2186 bp insert of clone $\lambda$ HuHITI-11000 (M. Diarra-Mehrpour and J.-P. Salier, unpublished results) covering about $70 \%$ of the full-length $H I$ cDNA from its $3^{\prime}$ end. The $H 2$ cDNA probe was the EcoR I-EcoR I, 1140 bp insert of clone $\lambda$ HuHITI-9 (Salier et al. 1987) covering about the central 35\% of the full-length $H 2$ cDNA. The $H 3$ cDNA probe was a mixture of an EcoR I-BamH I, 1485 bp segment and a Taq I-Taq I, 772 bp segment that are contiguous within the insert from clone $\lambda$ HuHITI-131 (Diarra-Mehrpour et al. 1989); together both segments cover about $70 \%$ of the full-length $H 3$ cDNA from its $3^{\prime}$ end.

\section{Mouse strains}

Mice of both sexes were at least 35 days old when used. $A / J(A)$, C57BL/6J (B), AXB $F_{1}$ and BXA F $F_{1}$ were purchased from The Jackson Laboratory and maintained in the University of Michigan animal quarters. DNA from recombinant inbred (RI) lines between the $\mathbf{A} / \mathbf{J}$ and C57BL/6J strains (AXB, BXA) (Nesbitt and Skamene 1984) were provided by M. Nesbitt, San Diego, Calif., while the computerized strain distribution pattern (SDP) for these RI lines is maintained by B. Paigen, Bar Harbor, Me. DNA from other inbred strains was purchased from The Jackson Laboratory.

\section{Mouse mRNAs}

Poly $(\mathrm{A})^{+} \mathrm{mRNAs}$ were purified from mouse liver by an acid guanidinium thiocyanate-phenol-chloroform extraction protocol (Chom- czynski and Sacchi 1987). They were electrophoresed along with an RNA ladder (0.24-9.5 kb from Gibco-BRL) in a denaturing formaldehyde/agarose gel following standard procedures. They were then blotted overnight in $15 \times \mathrm{SSPE}(20 \times \mathrm{SSPE}$ is $3 \mathrm{M} \mathrm{NaCl}, 200 \mathrm{~mm}$ $\mathrm{NaH}_{2} \mathrm{PO}_{4}, 20 \mathrm{~mm}$ EDTA, pH 7.4) onto an Hybond $\mathrm{N}$ nylon membrane (Amersham) and cross linked by UV exposure according to Reed and Mann (1985).

\section{Genomic DNA isolation and restriction}

For standard electrophoresis in agarose gel, genomic DNA was isolated from mouse spleens or livers (fasted for $24 \mathrm{~h}$ ) by the usual phenol/chloroform extractions and ethanol precipitation and stored in a Tris $10 \mathrm{~mm}$, EDTA $1 \mathrm{~mm}$, pH 7.5 buffer. For PFGE, genomic DNA from freshly isolated mouse spleens was prepared and stored in agarose blocks to prevent any shearing as already described (Verga and Erickson 1990).

The purified DNAs kept in solution or in agarose blocks were digested overnight to completion with at least ten units restriction endonuclease (from Boehringer-Mannheim or New England Biolabs) per $\mu \mathrm{g}$ DNA. DNA blocks for PFGE were equilibrated in restriction enzyme buffer prior to digestion, and re-equilibrated in Tris $10 \mathrm{~mm}$, EDTA $1 \mathrm{~mm}$ pH 8.0 prior to electrophoresis.

\section{DNA electrophoreses and blotting}

Mouse total genomic DNA was electrophoresed in a horizontal $0.8 \%$ agarose gel in a $1 \times \mathrm{TBE}(10 \times \mathrm{TBE}$ is $900 \mathrm{~mm}$ Tris, $900 \mathrm{~mm}$ borate, $10 \mathrm{~mm}$ EDTA buffer $\mathrm{pH} 8.2$ ) at 2-3 V/cm for $16 \mathrm{~h}$. The $1 \mathrm{~kb}$ DNA ladder from Gibco-BRL was used as a size marker. Alternatively, PFGE for human or mouse genomic DNA was performed in a Pulsaphor (Pharmacia-LKB) with an hexagonal electrode. The following conditions were used: $1 \%$ agarose gel in $0.25 \times \mathrm{TBE}, 150 \mathrm{~V}, 90$ $\mathrm{mA}, 65 \mathrm{~s}$ switch time, for $41 \mathrm{~h}$ at $12^{\circ} \mathrm{C}$. Concatamers of phage $\lambda$ (Pharmacia) were used as size markers.

After electrophoresis, the agarose gel was stained with ethidium bromide and photographed. The gel was soaked $(2 \times 10 \mathrm{~min})$ in $\mathrm{HCl}$ $0.15 \mathrm{~N}$ for DNA nicking and then it was soaked in $0.5 \mathrm{~N} \mathrm{NaOH}$ for $30 \mathrm{~min}$, and blotted in the same $\mathrm{NaOH}$ solution for 18-24 h onto a GeneScreen (Dupont) or a Bio-Trace RP (Gelman) nylon membrane. The membrane was then neutralized in $2 \times$ SSPE for $5 \mathrm{~min}$ and air dried.

\section{Hybridizations}

All cDNA probes were labeled with $\left(\alpha^{32} \mathrm{P}\right) \mathrm{dCTP}(3000 \mathrm{Ci} / \mathrm{mmole}$, Amersham) to a specific activity of $0.5-2.10^{9} \mathrm{cpm} / \mu \mathrm{g}$ by the random oligonucleotide procedure.

Hybridizations of RNA or DNA filters were carried out at $42^{\circ} \mathrm{C}$ for $16-48 \mathrm{~h}$ in $30 \%$ deionized formamide, $50 \mathrm{~mm}$ Tris $\mathrm{pH} 7.5,1 \mathrm{M}$ $\mathrm{NaCl}, 10 \%$ dextran sulfate, $0.1 \%$ SDS, $10 \times$ Denhardt's solution (50) solution is $1 \%$ polyvinylpyrrolidone, $1 \%$ ficoll, $1 \%$ bovine serum albumin), $100 \mu \mathrm{g} / \mathrm{ml}$ heat-denatured herring sperm DNA. Posthybridization washes were done in $2 \times \mathrm{SSPE}, 0.5 \%$ SDS at room temperature $(4 \times 5 \mathrm{~min})$ and at $60^{\circ} \mathrm{C}(2 \times 1 \mathrm{~h})$. The membrane was then autoradiographed onto an X-ray film (XAR-5, Kodak) with intensifying screen for $1-10$ days at $-80^{\circ} \mathrm{C}$. Prior to re-probing, the RNA membranes were de-hybridized by a $5 \mathrm{~min}$ wash in a boiling solution of $1 \%$ SDS and a second wash in the same solution at $65^{\circ} \mathrm{C}$ for $30 \mathrm{~min}$, and stored dry. The DNA membranes were dehybridized at room temperature by washes in $\mathrm{NaOH} 0.4 \mathrm{~N}(2 \times 15$ $\mathrm{min})$ and in $2 \times$ SSPE, $0.5 \%$ SDS $(2 \times 15 \mathrm{~min})$, then re-exposed for checking the de-hybridization efficiency, and dried for storage.

\section{Results}

Analysis of mouse liver poly $(A)^{+}$RNAs

Human $H 1, H 2, H 3, A 1 m$ or bikunin cDNA probes were hybridized to nylon membranes that contained 


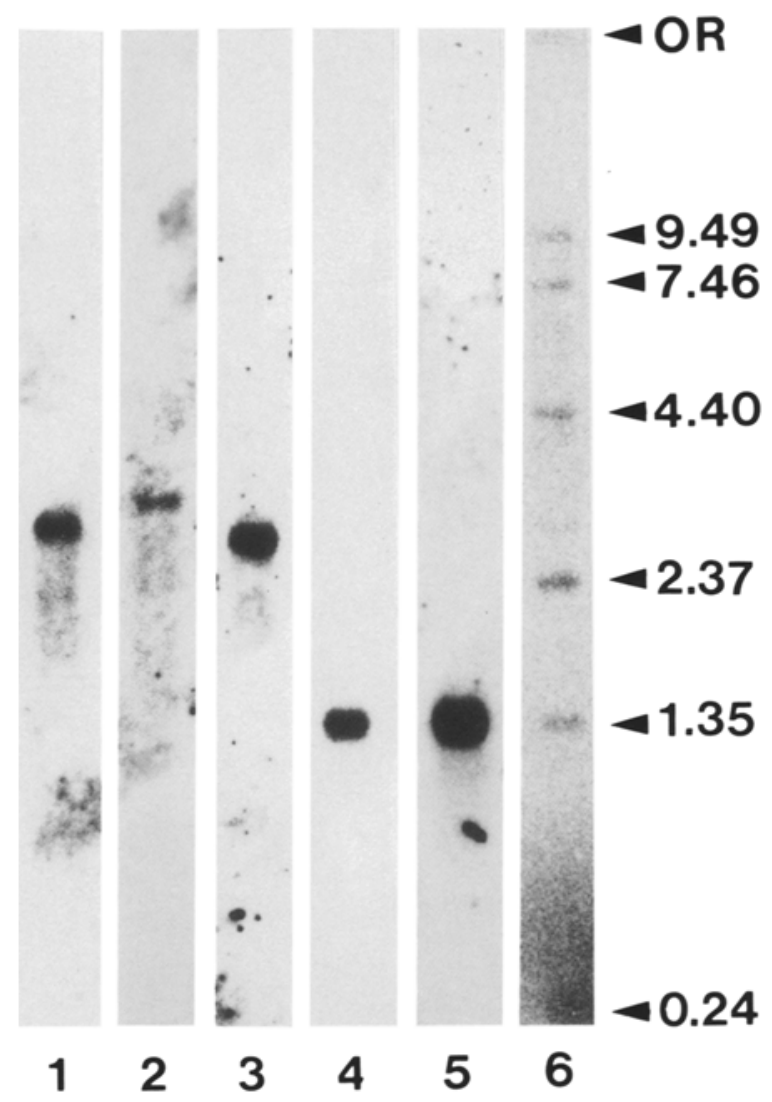

Fig. 1. RNA blot analysis of poly(A) ${ }^{+}$RNAs from mouse liver. Aliquots of $1 \mu \mathrm{g}$ poly $(\mathrm{A})^{+}$RNAs were separated in a denaturing agarose gel, blotted, and the resulting nylon strips were separately hybridized with either of various human $I \alpha I \mathrm{cDNA}$ probes. Lane 1: $H I$ probe; lane 2: $H 2$ probe; lane 3: $H 3$ probe; lane 4: $A I m$ (L chain) probe; lane 5: bikunin (L chain) probe; lane 6: RNA ladder in kb. OR means origin. Anode at the bottom.

electrophoretically separated liver poly(A) ${ }^{+}$RNAs from the Swiss mouse strain (the original, noncongenic strain from Lausanne, Switzerland). As shown in Fig. 1 each human probe recognized a population of mouse RNAs: the $H 1, H 2$ or $H 3$ chain probes detected a $3.0,3.2$, or $2.9 \mathrm{~kb}( \pm 0.1 \mathrm{~kb}) \mathrm{RNA}$ band, respectively, whereas the $\mathrm{L}$ chain probes, namely Alm or bikunin cDNAs, detected the same 1.3 $\mathrm{kb}$ band. Using successive hybridizations of a single RNA lane with each of the three $\mathrm{H}$ chain probes with- out intermediate dehybridizations, we precisely verified that the three $\mathrm{H}$ chain RNAs indeed differ in sizes (not shown).

\section{Patterns of restriction fragments in mouse $I \alpha I$ genes}

Genomic DNA from mouse strains A/J or C57BL/6J was digested with a series of common restriction endonucleases (four or six base cutters) and the pattern of resulting DNA fragments was analyzed by blot hybridization with each of four human $I \alpha I$ cDNA probes, namely $H 1, H 2, H 3$ or the complete $L$ probe (A1m + bikunin cDNAs). Typical results obtained with several enzymes are summarized in Table 1. Each enzyme/ probe combination revealed a characteristic set of restriction fragments and most fragments were found with only one enzyme/probe combination. Overall, the results suggested that the four different cDNA probes detected four different genes.

\section{PFGE fragments of mouse I $\alpha$ I genes}

A similar analysis was performed with the genomic DNA from $\mathrm{A} / \mathrm{J}$ or $\mathrm{C} 57 \mathrm{BL} / 6 \mathrm{~J}$ mouse strains and restriction enzymes that recognize rare sites in mammalian DNA. The restricted DNAs were separated by PFGE and blotted. The resulting filter was successively hybridized with each of the $I \alpha I$ probes. The results are presented in Fig. 2. The $H I$ and $H 3$ probes clearly revealed identical restriction fragments (smallest size: $130 \mathrm{~kb}$ with $K s p$ I or $S a l$ I) in mouse genomic DNA. Likewise, each of the $L$ probes, namely the $A 1 \mathrm{~m}$ or bikunin cDNAs, detected another, common set of restriction fragments. Finally, the $H 2$ probe revealed a third, distinct pattern of fragments. With some of the restriction enzymes tested, each probe did not show a sizeable hybridization band (Fig. 2). In such instances, most likely the $I \alpha I$-associated restriction fragments were quite large and retained within the zone of limited mobility (for example, lanes 3 and 4 in panel b) or were too small for the size range covered by the gel (lane 5 in panel b).

An Msp I polymorphism maps the mouse I $\mathrm{I} I$ L gene to Chr 4 near the brown locus

During the analysis of $I \alpha I$-related restriction fragments in mouse DNA, as described above, possible RFLPs

Table 1. Sizes of restriction fragments revealed by various, human $I \alpha I$ cDNA probes in genomic DNA from A/J or C57BL/6J mouse strains. ${ }^{a}$ Sizes are in $\mathrm{kb}$.

\begin{tabular}{lllll}
\hline Probe $^{\mathrm{b}}$ & $H I$ & $H 2$ & $H 3$ & $L^{\mathrm{c}}$ \\
\hline Restriction Endonuclease & & & & \\
Hinc II & $1.8 / 1.2 / .9$ & $6.0 / 3.9 / 1.9$ & $6.0 / 3.2 / 2.1$ & $6.0 / 2.2 / 1.9$ \\
& & $1.5 / 1.2 / 1.1 / 1.0$ & $1.5 / 8$ & 2.9 \\
Pst I & $4.5 / 1.8 / 1.2$ & $6.3 / 1.3$ & $4.5 / 2.9 / 2.5 / 1.3$ & $4.5 / 2.5 / 1.9$ \\
Pvu II & $1.7 / 1.5 / 1.35$ & $5.8 / 4.3 / 3.8 / 2.0$ & $4.0 / 3.5 / 2.8$ & 6.0 \\
Sac I & $5.5 / 2.8 / 2.5 / 1.5$ & $4.6 / 3.7$ & $2.5 / 1.8$ & 4.6 \\
Stu I & $3.8 / 1.8$ & $8.0 / 5.0$ & $3.6 / 1.8 / 1.3$ & $4.0 / 1.85 / 1.6$
\end{tabular}

a The restriction fragments obtained with the five enzymes indicated were identical in both strains.

b Described in Materials and methods.

${ }^{c} \mathrm{~L}$ probe $=$ A1m $\mathrm{cDNA}+$ bikunin cDNA. 


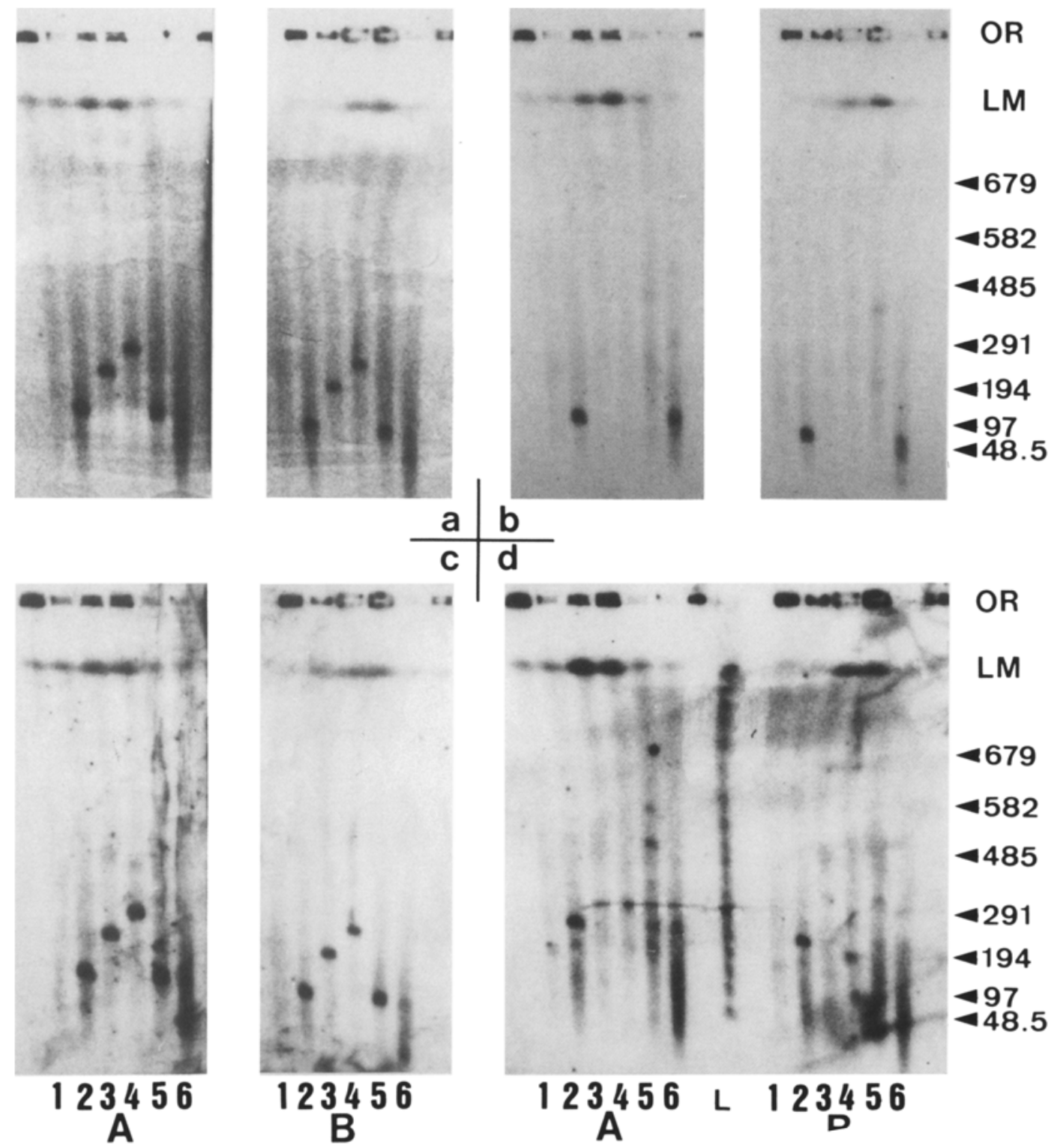

Fig. 2. Large restriction fragments revealed by various, human $I \alpha I$ cDNA probes in mouse genomic DNA separated by PFGE. Genomic DNA from A/J (panel A) or C57BL/6J (panel B) mouse strains was digested with various endonucleases: $\mathrm{Cla}$ I (lane 1); $K s p$ I (lane 2); Mlu I (lane 3); Not I (lane 4); Sal I (lane 5); Sma I (lane 6). The DNA digests were separated in a single PFGE gel and blotted. The resulting membrane was successively hybridized with the following human cDNA probes: $H 1$ (panel a), $H 2$ (panel b), $H 3$ (panel c), $L$

(Alm or bikunin cDNAs; panel d). Identical results were obtained when using either Alm or bikunin cDNAs and therefore only one corresponding autoradiography is shown. The size markers are shown in lane $\mathbf{L}$ and the sizes in $\mathrm{kb}$ are on the right. OR is origin. $\mathrm{LM}$ is zone of limited mobility. Anode at the bottom. Please note: (1) a slight difference in migration velocity between the left and right side of the gel (panel A versus B); and (2) possible Not I and Sal I RFLPs for the $L$ chain gene that are currently the subject of investigations.

were also investigated by comparison of the $A / J(A)$ and $\mathrm{C} 57 \mathrm{BL} / 6 \mathrm{~J}$ (B) mouse strains. DNAs restricted with a series of 17 restriction enzymes (Apa I, Dra I, EcoR I, Hae III, Hinc II, Hind III, Hinf I, Kpn I, Msp I, Nci I, Pst I, Pvu II, Rsa I, Sac I, Sca I, Stu I, Taq I) were successively blot-hybridized with each of the three human probes for the $H 1, H 2, H 3$ genes and the complete human $L$ probe (A1m + bikunin cDNAs). An RFLP for the $L$ gene was found with $M s p$ I that revealed a 2.6 or $3.0 \mathrm{~kb}$ allelic fragment as illustrated in Fig. 3. Further, separate hybridizations with the A1m or bikunin cDNA probes of the $\mathrm{L}$ chain gene indicated that this RFLP was detected by the A1m cDNA (Fig.
3). The $2.6 \mathrm{~kb}$ genotype was found in the $\mathrm{A} / \mathrm{J}, \mathrm{BALB} /$ $\mathrm{cJ}$ and $\mathrm{C} 3 \mathrm{H} / \mathrm{HeJ}$ mouse strains whereas the $3.0 \mathrm{~kb}$ genotype was found in the $129 / \mathrm{J}, \mathrm{C} 57 \mathrm{BL} / 6 \mathrm{~J}, \mathrm{C} 57 \mathrm{BL} /$ 10J, CBA/J, C58/J, DBA/2J and NZW strains (not shown).

The distribution of this RFLP was determined in all available AXB and BXA RI strains (Fig. 3 and Table 2) and the SDP compared to other polymorphic genes already typed in this RI strain set. Linkage was found to $b$, a coat color gene on $\mathrm{Chr} 4$. There were five mismatches with $b$ among 41 strains giving a map distance of $3.7 \pm 1.9 \mathrm{cM}(95 \%$ confidence interval 1.1$10.8 \mathrm{cM}$ ) calculated according to Silver and Buckler 


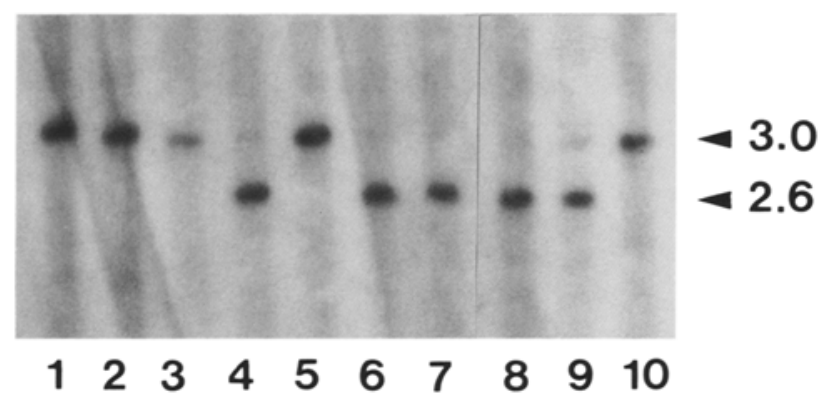

Fig. 3. Msp I RFLP in the $I \alpha I \mathrm{~L}$ chain gene of various mouse strains. Msp I-restricted DNA from various mouse strains was hybridized with the Alm cDNA probe. This probe detects a 2.6 or 3.0 $\mathrm{kb}$ allelic band. The patterns from AXB 1,3,4,5,12, 17, 25, or BXA 1, 7, 8 RI mouse strains are shown in lanes 1-10, respectively. Sizes in $\mathrm{kb}$ on the right. Anode at the bottom.

(1986). The $I \alpha I L$ gene (proposed symbol Intin-4) showed linkage with Mup-1 (six mismatches in 40 strains for a map distance of $4.9 \pm 2.4 \mathrm{cM}$ ), but not with $P m v-23$ (16 mismatches in 39 strains), suggesting a gene order of Mup-I, Intin-4, $b$ and Pmv-23.

\section{Discussion}

A very limited number of reports have dealt with $I \alpha I$ or other Kunitz-type protease inhibitors in rodents (Kastern et al. 1986; Kido et al. 1988; Fukuchi et al. 1989 ) and nothing is known about $I \alpha I$ genes in nonprimate species. Therefore, and given the complexity of $I \alpha I$ genes in human, we have been interested in looking at $I \alpha I$ gene organization in a rather distant mammalian group to seek insights on the origin and evolution of this set of genes.

In hybridization experiments, five human cDNA probes were used, namely the $H 1, H 2$ and $H 3$ cDNAs and the two $\mathrm{L}$ chain-related $\mathrm{A} 1 \mathrm{~m}$ - or bikunin-encoding cDNAs. The three $\mathrm{H}$ chain cDNAs are evolutionarily related (Diarra-Mehrpour et al. 1989) and the two L chain cDNAs code for distinct proteins that originate from a common $\mathrm{L}$ precursor in human (Kaumeyer et al. 1986). Since each of these five human probes could detect a limited number of bands on Southern hybridizations with mouse genomic DNA (Table 1 and Fig. 2 ), we conclude that nucleotide sequence similarities in $I \alpha I$-related, single-copy genes exist between mouse and human. Despite the evolutionary relationships between the $H 1, H 2$ and $H 3$ genes, the quite different patterns of bands seen in Northern or Southern blots with the $H 1, H 2$ or $H 3$ probes indicate that no spurious cross-hybridization between each mouse $I \alpha I \mathrm{H}$ chain RNA or gene and several of our human probes took place under the hybridization stringency used. We propose mouse gene symbols for $H 1, H 2$ and $H 3$ of Intin-1, Intin-2, and Intin-3, with Intin-4 for the L chain gene.

The same-sized, $1.3 \mathrm{~kb}$ mRNA population was detected with both $\mathrm{A} 1 \mathrm{~m}$ and bikunin probes in mouse liver (Fig. 1), in agreement with previous results obtained in human (Salier et al. 1987) and pig (Gebhard et al. 1990b). Furthermore, a same restriction pattern of mouse DNA was seen when either the A1m or bikunin probe was used to detect restriction fragments in PFGE experiments (Fig. 2). Therefore, we conclude that in mouse, as in human (Kaumeyer et al. 1986; Salier et al. 1987; Vetr et al. 1989; Diarra-Mehrpour et al. 1990), a single gene (or identically duplicated genes) and mRNA code for a $\mathrm{L}$ chain precursor molecule comprised of $\mathrm{A} 1 \mathrm{~m}$ and bikunin. Likewise, A1m in rat is encoded by a $1.25 \mathrm{~kb}$ mRNA (Kastern et al. 1986). Given our present results in mouse, it is likely that this rat RNA in fact codes for a tandem A1m/bikunin precursor.

Table 2. Distribution pattern of mouse $I \alpha I L$ gene $M s p$ I RFLP in AXB and BXA RI strains.

\begin{tabular}{|c|c|c|c|c|c|c|c|c|c|c|c|c|c|c|c|c|c|c|c|c|c|c|c|c|}
\hline \multicolumn{25}{|l|}{$\mathrm{AXB}^{\mathrm{a}}$} \\
\hline Strain & 1 & 2 & 3 & 4 & 5 & 6 & 7 & 8 & 9 & 10 & 11 & 12 & 13 & 14 & 15 & 17 & 18 & 19 & 20 & 21 & 22 & 23 & 24 & 25 \\
\hline Mup-1 $1^{\mathrm{b}}$ & $\mathrm{B}^{\mathrm{c}}$ & A & B & B & A & B & $\mathrm{B}$ & A & $\mathrm{U}^{\mathrm{d}}$ & B & A & B & $A$ & B & B & A & $\mathrm{U}$ & B & B & B & A & B & $\begin{array}{l}\mathrm{B} \\
\mathrm{X}\end{array}$ & A \\
\hline Intin-4 & B & A & B & B & $\mathrm{A}$ & $\begin{array}{l}\text { B } \\
\text { X }\end{array}$ & B & A & B & B & A & B & A & $\begin{array}{l}\text { B } \\
X\end{array}$ & B & A & B & B & B & $\begin{array}{l}B \\
X\end{array}$ & A & B & $\begin{array}{l}\mathrm{A} \\
\mathrm{X}\end{array}$ & A \\
\hline$b^{\mathrm{b}}$ & $\begin{array}{l}\text { B } \\
\text { X }\end{array}$ & A & B & B & $\begin{array}{l}A \\
X\end{array}$ & A & $\begin{array}{l}\mathrm{B} \\
\mathrm{X}\end{array}$ & A & B & $\begin{array}{l}\mathrm{B} \\
\mathrm{X}\end{array}$ & $\begin{array}{l}\mathrm{A} \\
\mathrm{X}\end{array}$ & B & A & A & B & A & $\begin{array}{l}B \\
X\end{array}$ & B & B & A & $\begin{array}{l}\mathrm{A} \\
\mathrm{X}\end{array}$ & $\begin{array}{l}\text { B } \\
\text { X }\end{array}$ & B & A \\
\hline$P m v-23^{b}$ & A & A & B & B & $\mathrm{B}$ & A & A & A & B & A & B & B & A & A & $U$ & $\mathbf{U}$ & A & $\mathrm{U}$ & B & A & B & A & B & A \\
\hline \multicolumn{25}{|l|}{$\mathrm{BXA}^{\mathrm{e}}$} \\
\hline Strain & 1 & 2 & & 4 & & & 7 & 8 & 9 & & 11 & 12 & 13 & 14 & 16 & 17 & 18 & 19 & 20 & & 22 & 23 & 24 & 25 \\
\hline$M u p-I^{\mathrm{b}}$ & A & A & & $\begin{array}{l}\mathrm{A} \\
\mathrm{X}\end{array}$ & & & A & B & A & & $\mathrm{U}$ & A & A & B & A & B & A & A & A & & $\begin{array}{l}\mathrm{A} \\
\mathrm{X}\end{array}$ & $\begin{array}{l}\text { B } \\
\mathrm{X}\end{array}$ & $\begin{array}{l}\mathrm{A} \\
\mathrm{X}\end{array}$ & $\begin{array}{l}\text { B } \\
X\end{array}$ \\
\hline Intin-4 & A & A & & $\begin{array}{l}B \\
X\end{array}$ & & & A & B & A & & B & A & A & B & A & B & A & A & A & & B & A & B & A \\
\hline$b^{\mathrm{b}}$ & A & A & & $\begin{array}{l}\mathrm{A} \\
\mathrm{X}\end{array}$ & & & $\begin{array}{l}\mathrm{A} \\
\mathrm{X}\end{array}$ & B & A & & $\begin{array}{l}\text { B } \\
X\end{array}$ & A & A & B & A & B & $\mathrm{U}$ & $\mathrm{U}$ & A & & $\begin{array}{l}\mathbf{B} \\
X\end{array}$ & $\begin{array}{l}\mathrm{A} \\
\mathrm{X}\end{array}$ & $\begin{array}{l}\mathrm{B} \\
\mathrm{X}\end{array}$ & A \\
\hline$P m v-23^{\mathrm{b}}$ & A & A & & B & & & B & B & A & & A & A & A & B & $\mathrm{U}$ & B & A & A & A & & B & B & A & A \\
\hline
\end{tabular}


In the present study we describe for the first time a polymorphism of mouse $I \alpha I L$ gene, namely an $M s p$ I RFLP. Through linkage analysis in RI lines, this RFLP allowed us to precisely map this $L$ gene (Intin-4) in very close proximity to the $b$ locus on mouse Chr 4 . The q34 band of chr 9 in human is homologous to this region of mouse Chr 4 (Searle et al. 1989). Therefore, our results suggest that the human $I \alpha I \mathrm{~L}$ gene is located at $9 q 34$, although it was previously localized at 9q32-q33 by the lower resolution of in situ hybridization onto metaphasic chromosomes (Diarra-Mehrpour et al. 1989).

The human $H 1, H 2$ and $H 3$ probes detected three poly(A) ${ }^{+}$RNA populations in mouse liver. The size range (2.9-3.2 kb) measured for these RNA populations is close to the range $(3.0-3.3 \mathrm{~kb})$ seen for human $H 1, H 2$ and $H 3$ chain poly(A) ${ }^{+}$RNAs (Salier et al. 1987; Diarra-Mehrpour et al. 1989). The human $H$, $\mathrm{H} 2$ and $H 3$ probes also revealed distinct sets of restriction fragments in Southern analysis of mouse DNA (Table 1). This suggests that these three probes detected three distinct mouse $H$ genes. Furthermore, the $H l$ and $H 3$ probes exhibited the same pattern of bands (130 kb or more) in PFGE experiments, which demonstrates a close, tandem arrangement of the $H I$ and $H 3$ genes within $130 \mathrm{~kb}$ in the mouse genome. This is reminiscent of co-localization of the human $\mathrm{Hl}$ and $\mathrm{H3}$ genes at band 3p21.1-21.2 (Diarra-Mehrpour et al. 1989) where further, recent results indicate that these two genes are tandemly arranged within less than 100 $\mathrm{kb}$ (J.-P. Salier, unpublished results).

Overall, our present results show that in mouse as well as in human, $I \alpha I$ and/or related molecules are encoded by four discrete genes, including one $L$ gene of homologous chromosomal localization, an $\mathrm{H} 2$ gene, and two $H I$ and $H 3$ genes in a tandem arrangement. These four genes are transcribed in the liver. A comparison of amino acid or nucleotide sequence between $H 1, H 2$ and $H 3$ chains or cDNAs in human, has shown that $H 3$ and $H I$ sequences are highly similar and $H I$ and $H 2$ sequences are most distantly related (DiarraMehrpour et al. 1989). Therefore, the following order of appearance of $H$ chain genes was suggested: (1) the $H 2$ gene originated from an $H 3$ ancestor gene; and (2) more recently, $H I$ originated from a duplication of the $H 3$ ancestor gene (Diarra-Mehrpour et al. 1989). Our present observations of homologous organizations of $I \alpha I$ genes in human and mouse indicate that such a triplication of the $H 3$ ancestor gene occurred prior to the divergence of human and mouse from a common ancestor about 80 million years ago. It will be of interest to analyze whether similar amino acid sequences and enzyme specificities of the protease inhibitory sites in the bikunin moiety have been conserved in mouse and human or whether they have extensively diverged despite highly conserved, surrounding sequences. The second event has been reported for other protease inhibitors with a common ancestor, namely human $\alpha$-1-antichymotrypsin and mouse contrapsin (Hill et al. 1984).
Acknowledgments. We thank Ann Sweet for technical assistance; Dr. Beverly Paigen, The Jackson Laboratory, Bar Harbor, Me., for maintaining the AXB and BXA RI line data, and for helping in computerized analysis of mouse loci; and Annette Spurr for secretarial assistance. This work was supported by the University of Rouen, France, a National Institutes of Health grant HD 26454 to R.P. Erickson and a North Atlantic Treaty Organization grant to R.P. Erickson and J.-P. Salier.

\section{References}

Bourguignon, J., Vercaigne, D., Sesboue, R., Martin, J.P., and Salier, J.P.: Inter- $\propto$-trypsin inhibitor (ITI): Two distinct mRNAs in baboon liver argue for a discrete synthesis of $I T I$ and $I T I$ derivatives. FEBS Lett 162: 379-383, 1983.

Bourguignon, J., Diarra-Mehrpour, M., Sesboue, R., Frain, M., Sala-Trepat, J.M., Martin, J.P., and Salier, J.P.: Human inter- $\alpha-$ trypsin inhibitor: Characterization and partial nucleotide sequencing of a light chain-encoding cDNA. Biochem Biophys Res Comm 131: 1146-1153, 1985.

Chomczynski, P. and Sacchi, N.: Single-step method of RNA isolation by acid guanidinium thiocyanate-phenol-chloroform extraction. Anal Biochem 162: 156-159, 1987.

Diarra-Mehrpour, M., Bourguignon, J., Sesboue, R., Mattei, M.G., Passage, E., Salier, J.P., and Martin, J.P.: Human plasma inter$\alpha$-trypsin inhibitor is encoded by four genes on three chromosomes. Eur J Biochem 179: 147-154, 1989.

Diarra-Mehrpour, M., Bourguignon, J., Sesboue, R., Salier, J.P. Leveillard, T., and Martin, J.P.: Structural analysis of the human inter- $\alpha$-trypsin inhibitor light-chain gene. Eur J Biochem 191: 131$139,1990$.

Enghild, J.J., Thogersen, I.B., Pizzo, S.V., and Salvesen, G.: Analysis of inter- $\alpha$-trypsin inhibitor and a novel trypsin inhibitor, Pre$\alpha$-trypsin inhibitor, from human plasma. Polypeptide chain stoichiometry and assembly by glycan. $J$ Biol Chem 264: 1597515981, 1989.

Fukuchi, K.I., Martin, G.M., and Deeb, S.S.: Sequence of the protease inhibitor domain of the A4 amyloid protein precursor of $M u s$ domesticus. Nucl Acids Res 17: 5396, 1989.

Gebhard, W. and Hochstrasser, K.: Inter- $\alpha$-trypsin inhibitor and its close relatives. In A.J. Barrett and G. Salvesen (eds.); Proteinase Inhibitors, pp. 389-401, Elsevier, Amsterdam, 1986.

Gebhard, W., Schreitmuller, T., Hochstrasser, K., and Wachter, E.: Complementary DNA and derived amino acid sequence of the precursor of one of the three protein components of the inter- $\alpha$ trypsin inhibitor complex. FEBS Lett 229: 63-67, 1988.

Gebhard, W., Hochstrasser, K., Fritz, H., Enghild, J.J., Pizzo, S.V., and Salvesen, G.: Structure of inter- $\alpha$-inhibitor (inter- $\alpha$ trypsin inhibitor) and pre- $\alpha$-inhibitor: Current state and proposition of a new terminology. Hoppe-Seyler's Z Physiol Chem 371 (Suppl): 13-22, 1990a.

Gebhard, W., Schreitmuller, T., Vetr, H., Wachter, E., and Hochstrasser, K.: Complementary DNA and deduced amino acid sequences of porcine $\alpha 1$-microglobulin and bikunin. FEBS Lett 269: 32-36, 1990b.

Hill, R.E., Shaw, P.H., Boyd, P.A., Baumann, H., and Hastie, N.D.: Plasma protease inhibitors in mouse and man: Divergence within the reactive centre regions. Nature 311: 175-177, 1984.

Jessen, T.E., Faarvang, K.L., and Ploug, M.: Carbohydrate as covalent crosslink in human inter- $\alpha$-trypsin inhibitor: A novel plasma protein structure. FEBS Lett 230: 195-200, 1988.

Kastern, W., Bjorck, L., and Akerstrom, B.: Developmental and tissue-specific expression of $\alpha-1$-microglobulin mRNA in the rat. J Biol Chem 261: 15070-15074, 1986.

Kaumeyer, J.F., Polazzi, J.O., and Kotick, M.P.: The mRNA for a proteinase inhibitor related to the HI-30 domain of inter- $\alpha$-trypsin inhibitor also encodes $\alpha-1$-microglobulin (protein HC). Nucl Acids Res 14: 7839-7850, 1986.

Kido, H., Yokogoshi, Y., and Katunuma, N.: Kunitz-type protease inhibitor found in rat mast cells. Purification, properties, and amino acid sequence. $J$ Biol Chem 263: 18104-18107, 1988.

McKeehan, W.L., Sakagami, Y., Hoshi, H., and McKeehan, K.A.: 
Two apparent human endothelial cell growth factors from human hepatoma cells are tumor-associated proteinase inhibitors. $J$ Biol Chem 261: 5378-5383, 1986.

Nesbitt, M.N. and Skamene, E.: Recombinant inbred mouse strains derived from $\mathrm{A} / \mathrm{J}$ and $\mathrm{C} 57 \mathrm{BL} / 6 \mathrm{~J}$ : A tool for the study of genetic mechanisms in host resistance to infection and malignancy. $J$ Leukocyte Biol 36: 357-364, 1984.

Reed, K.C. and Mann, D.A.: Rapid transfer of DNA from agarose gels to nylon membranes. Nucl Acids Res 13: 7207-7221, 1985.

Salier, J.P.: Inter- $\alpha$-trypsin inhibitor: Emergence of a family within the Kunitz-type protease inhibitor superfamily. Trends Biochem Sci 15: 435-439, 1990.

Salier, J.P., Diarra-Mehrpour, M., Sesboue, R., Bourguignon, J., Benarous, R., Ohkubo, I., Kurachi, S., Kurachi, K., and Martin, J.P.: Isolation and characterization of cDNAs encoding the heavy chain of human inter- $\alpha$-trypsin inhibitor $(I \alpha T I)$ : Unambiguous evidence for multipolypeptide chain structure of I $\alpha T I$. Proc Natl Acad Sci USA 84: 8272-8276, 1987.

Searle, A.G., Peters, J., Lyon, M.F., Hall, J.G., Evans, E.P., Ed- wards, J.H., and Buckle, V.J.: Chromosome maps of man and mouse. IV. Ann Hum Genet 53: 89-140, 1989.

Silver, J. and Buckler, C.E.: Statistical considerations for linkage analysis using recombinant inbred strains and backcrosses. Proc Natl Acad Sci USA 83: 1423-1427, 1986.

Verga, V. and Erickson, R.P.: Pulsed field gel electrophoresis and its application to human and mouse sex-determination. In K.W. Adolph (ed.); Advanced Techniques in Chromosome Research, pp. 155-180, Marckel Dekker, New York, 1990.

Vetr, H., Kogler, M., and Gebhard, W.: The domain structure of the inhibitor subunit of human inter- $\alpha$-trypsin inhibitor reflects the exon structure of its gene. FEBS Lett 245: 137-140, 1989.

Wachter, E. and Hochstrasser, K.: Kunitz-type proteinase inhibitors derived by limited proteolysis of the inter- $\alpha$-trypsin inhibitor. III. Sequence of the two Kunitz-type domains inside the native inter- $\alpha$-trypsin inhibitor, its biological aspects and also of its cleavage products. Hoppe-Seyler's Z Physiol Chem 360: 13051311, 1979. 